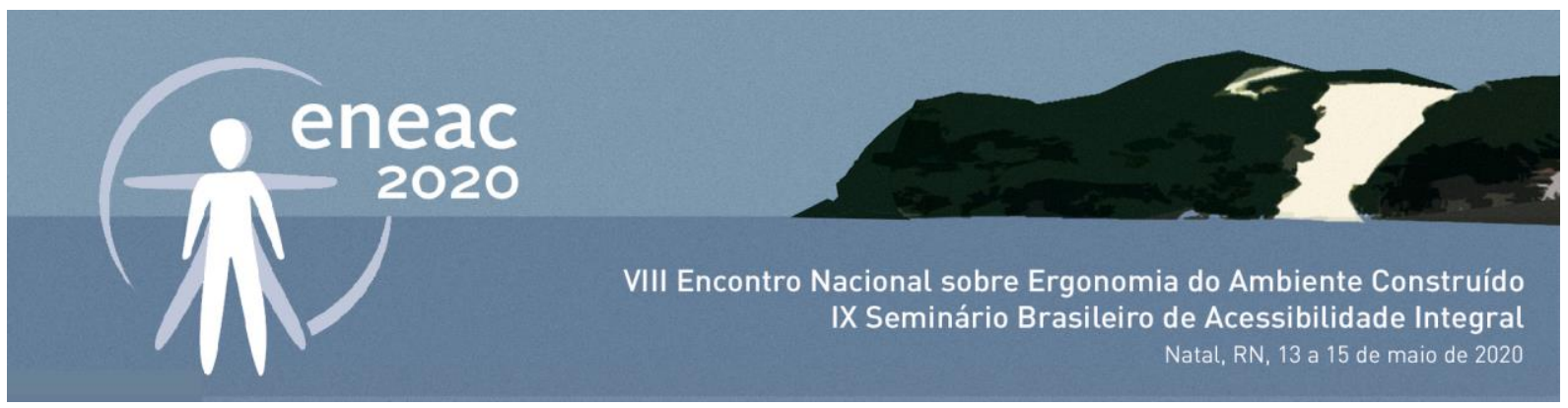

\title{
Hotéis executivos acessíveis: estudo comparado de dois hotéis em Fortaleza-Brasil
}

\author{
Affordable business hotels: comparative study of two hotels in \\ Fortaleza-Brazil
}

MANUELA DE CASTRO MENDONÇA LIMA

Pós-Graduanda, Universidade Federal do Ceará, manucml@gmail.com

CARLOS BRUNO OLIVEIRA ROCHA

Graduando, Universidade Federal do Ceará, carlosoliveira@arquitetura.ufc.br

ZILSA MARIA PINTO SANTIAGO

Doutora, Universidade Federal do Ceará, zilsa@arquitetura.ufc.br

\begin{abstract}
RESUMO
Nos últimos vinte anos, Fortaleza tornou-se destaque no país como uma das cidades mais procuradas para o turismo de lazer. Belas praias e sol durante o ano todo sempre foram os principais fatores que atraíram os turistas para a capital do Ceará; lotando seus hotéis à beira-mar. Porém, o mercado executivo também começou a crescer na cidade por meio de grandes eventos em diversos ramos. Fortaleza passou a ser uma cidade de negócios, necessitando de novos empreendimentos voltados para a hospedagem deste público específico que não tem como único objetivo o turismo de lazer. Assim, o presente artigo tem como finalidade a avaliação de dois novos hotéis executivos localizados em Fortaleza e a sua acessibilidade física; pois, ao serem edificações construídas recentemente, espera-se que apresentem um desenho acessível para os hóspedes.
\end{abstract}

PALAVRAS-CHAVE: Hotéis, acessibilidade, avaliação pós-ocupação

\begin{abstract}
In the last twenty years, Fortaleza has become prominent in the country as one of the most sought after cities for leisure tourism. Beautiful beaches and sunshine all year round have always been the main factors that attracted tourists to the capital of Ceará, crowding their beachfront hotels. However, the executive market has also begun to grow in the city through major events in various branches. Fortaleza has become a business city, needing new ventures aimed at hosting this specific public that has not only leisure tourism as its sole objective. Thus, this article aims to evaluate two new executive hotels located in Fortaleza and their physical accessibility; as they are newly built buildings, they must already have an accessible design for guests.
\end{abstract}

KEYWORDS: Hotels, accessibility, post occupation evaluation 


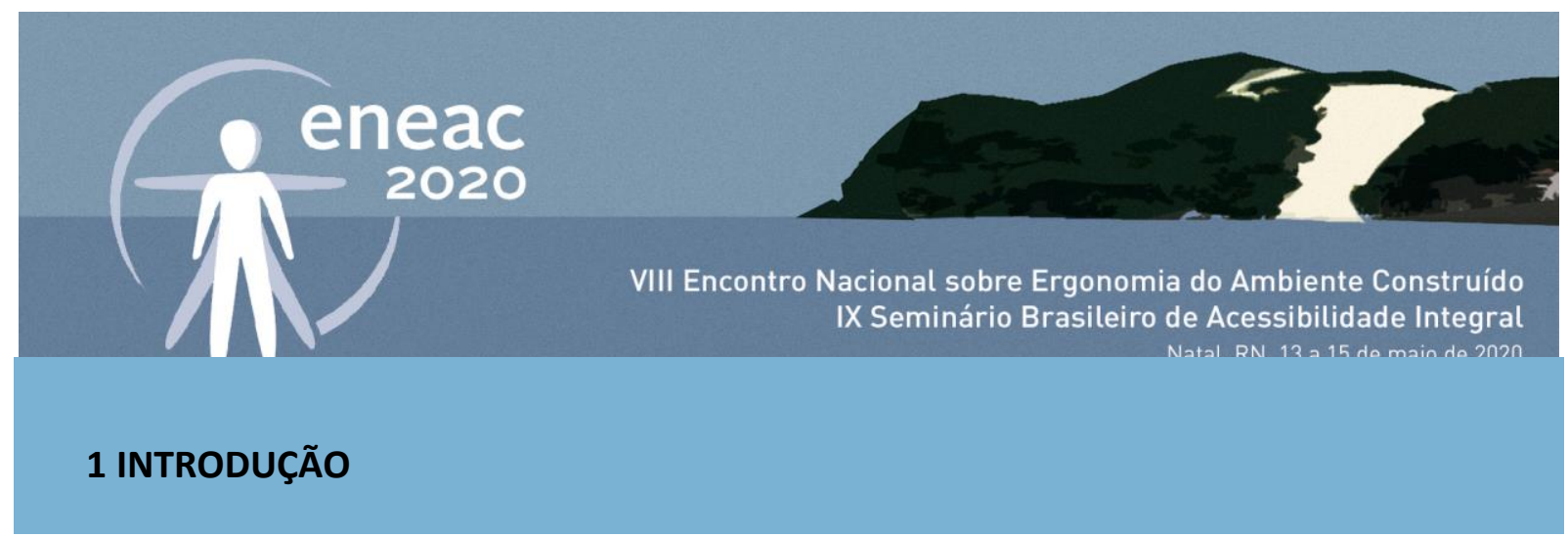

Com o imediatismo da sociedade atual, muitos serviços estão se especializando para atender mais e melhor os seus consumidores. Esta especialização que já era comum nas profissões, está avançando no campo da arquitetura e do urbanismo também. Algumas edificações e espaços abertos estão sendo desenvolvidos a partir de exigências pré-estabelecidas antes da fase projetual. Os programas de necessidades, realizados pelos profissionais da área, estão cada vez mais detalhados com a finalidade de não deixar passar qualquer falha que venha a ser, no futuro, ponto negativo para o estabelecimento.

A preocupação e o preciosismo com o atendimento do que é solicitado na fase do pré-projeto, também vem em decorrência da concorrência comercial e da necessidade em apresentar um diferencial. O mercado competitivo exige cada vez mais das pessoas e do que é oferecido, pois, se alguém ou algo novo surge, o antigo fica em desuso ou obsoleto automaticamente. Assim, a atualização constante é de suma importância para qualquer profissional ou empreendimento.

De acordo com a Nota técnica 01/2018 referente ao Censo Demográfico de 2010, 12.748.663 de pessoas declararam ter pelo menos uma das deficiências investigadas pelo Instituto Brasileiro de Geografia e Estatística (IBGE). Este valor corresponde a 6,7\% da população brasileira e pode ser utilizado como indicador de real demanda de usuários com deficiência. Tal informação tornou-se imprescindível no campo da arquitetura e do urbanismo nos quais os projetos consideram esse público como usuário. A princípio, a acessibilidade em projetos era vista como diferencial no mercado, hoje é indispensável para um espaço eficiente.

Ao se tratar de espaços eficientes, os padrões que tornam as edificações acessíveis também as capacitam para atender objetivos atuais do mercado competitivo. Isso ressalta a importância do Decreto Federal 5.296, de 2 de dezembro de 2004, e as normas vigentes relativas à acessibilidade e desenho universal, como a NBR 9.050/2015 e a NBR 16.537/2016. Estes documentos são guias para implementação de elementos que promovem o uso democrático por seus usuários, assegurando que o prédio corresponda de forma satisfatória o que é exigido pelo mercado.

Neste sentido, este trabalho busca analisar as condições de acessibilidade de dois hotéis de Fortaleza, levando em consideração itens como acesso, passeios, circulações horizontais e verticais, recepção, sinalização visual, mobiliário, entre outros. As análises desses espaços, a partir de relatórios, geraram resultados qualitativos das condições de mobilidade por pessoas com deficiência ou mobilidade reduzida dentro destes dois empreendimentos.

Ressaltando a diversidade da rede hoteleira de Fortaleza, que é majoritariamente presente na orla da cidade, foi com que os hotéis $A$ e $B^{i}$ com suas localizações diferenciadas, fossem analisados à luz das diretrizes vigentes em normas referentes à acessibilidade. Os resultados obtidos verificam o nível de comprometimento da edificação com a inclusão de pessoas com deficiência, idosos, crianças, entre outros.

\section{DEFINIÇÃO DOS HOTÉIS}

A escolha dos hotéis surgiu a partir de uma atividade que tinha como objetivo a análise das condições de acessibilidade em hotéis de Fortaleza. Esta atividade, parte integrante de uma pesquisa 


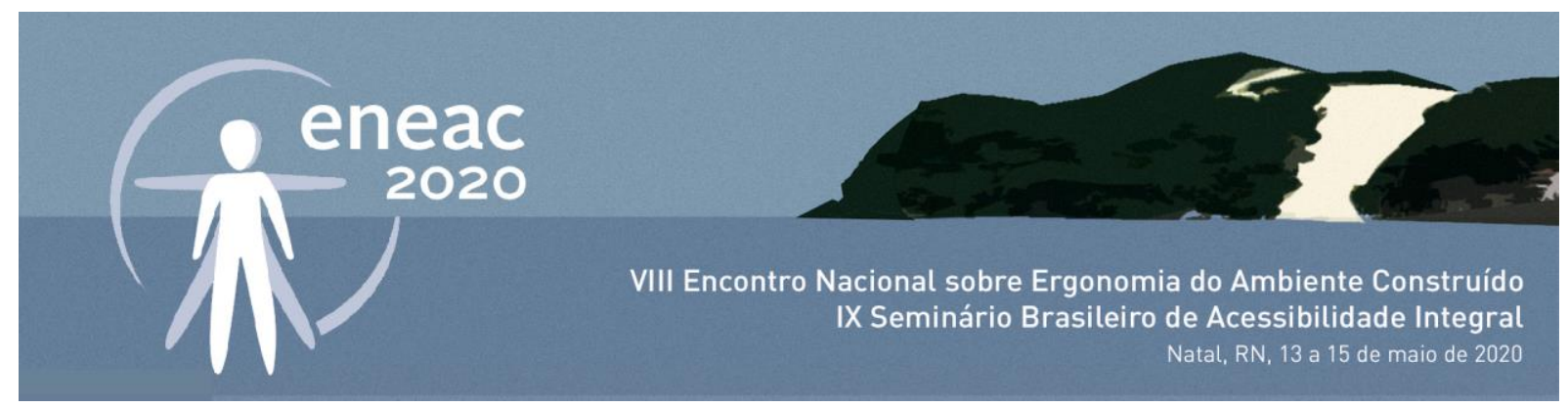

mais ampla sobre a rede hoteleira local, teve como justificativa a situação da cidade como sede dos jogos da Copa de 2014 e, por consequência, a sua submissão protocolar de adequação do turismo nacional.

Segundo informações do Governo do Estado do Ceará apresentadas no Quadro 1, a demanda hoteleira de Fortaleza ocorre de forma majoritária por motivação de lazer e passeio, mas, também, por motivos de negócios e trabalho; fomentando o desenvolvimento de hotéis em pontos estratégicos da cidade.

\begin{tabular}{|c|c|c|c|c|c|c|c|c|}
\hline \multirow{2}{*}{ Motivação } & \multicolumn{2}{|c|}{ Turistas } & \multirow{2}{*}{$\begin{array}{l}\text { Perm. } \\
\text { (dias) }\end{array}$} & \multicolumn{2}{|c|}{ Gastos (R\$) } & \multicolumn{2}{|c|}{ Receita Turística } & \multirow{2}{*}{$\begin{array}{l}\text { Impacto } \\
\text { no PIB(\%) }\end{array}$} \\
\hline & Total & $(\%)$ & & Percapita & Percapita/Dia & R\$ Milhões & $(\%)$ & \\
\hline Lazer/Passeio & 1.551 .530 & 46,4 & 12,8 & $2.331,20$ & 182,13 & $3.616,9$ & 49,5 & 5,8 \\
\hline Visita Parente/Amigo & 655.388 & 19,6 & 11,5 & $1.928,12$ & 167,66 & $1.263,7$ & 17,3 & 2,0 \\
\hline Negócios/Trabalho & 662.075 & 19,8 & 6,3 & $2.220,55$ & 352,47 & $1.470,2$ & 20,1 & 2,3 \\
\hline Congressos/Eventos & 357.788 & 10,7 & 5,5 & $2.298,50$ & 417,91 & 822,4 & 11,2 & 1,3 \\
\hline Outros & 117.034 & 3,5 & 8,4 & $1.970,23$ & 234,55 & 189,7 & 2,6 & 0,3 \\
\hline Total & 3.343.815 & 100,0 & 10,6 & $2.187,21$ & 206,34 & $7.313,6$ & 100,7 & 11,6 \\
\hline Fonte: SETUR/CE & & & & & & & & \\
\hline
\end{tabular}

Sabendo que a capital do Ceará é um lugar com um grande potencial turístico e tendo sua beira-mar como um dos pontos mais visitados pelos turistas, a grande maioria dos hotéis encontra-se margeando a orla de Fortaleza; concentrando-se nos bairros da Praia de Iracema, Meireles, Mucuripe e Praia do Futuro. Hotéis e pequenas pousadas, contudo, podem ser encontradas por toda a cidade, localizando-se em lugares estratégicos de geração de polos de viagens, como próximos às universidades, à rodoviária, aos centros de compras em atacado.

Mas, como fora dito, além do potencial turístico, Fortaleza despontou como uma cidade atrativa para a realização de eventos nacionais e internacionais; assim, o Governo do Estado, em meados do ano de 2007, decidiu construir um novo complexo para a realização de feiras e eventos - O Centro de Eventos do Ceará. Esta edificação, inaugurada em 2012, é localizada ao lado do terreno do antigo Centro de Convenções de Fortaleza, no bairro Edson Queiroz. Ressalta-se que, a localização é estratégica por estar endereçada em umas das avenidas de maior fluxo da cidade - Av. Washington Soares, e por essa ser uma via que possibilita o acesso à região litorânea leste do estado.

O projeto do novo Centro de Eventos foi lançado pelo governo estadual como parte de várias ações para potencializar a cidade diante de outras capitais do Brasil. Sabia-se, também, que nos dois anos seguintes à inauguração, Fortaleza seria uma das cidades brasileiras a receber alguns jogos da Copa das Confederações (2013) e do Mundo (2014); ou seja, para o governo, seria a oportunidade de uma projeção rápida da cidade como força turística e comercial, atraindo olhares de todos que ali passassem. O novo centro viria para contribuir para a identidade turística do estado e para melhorar os indicadores econômicos e sociais do turismo, através da redução das taxas de disponibilidade dos hotéis em períodos de baixa estação (LIMA, 2015).

Assim, com esta possível potencialização e com a localização favorável do Centro de Eventos, bairros vizinhos como o Guararapes, se viu em uma situação de oportunidade de crescimento comercial além do residencial já consolidado. Além disso, a presença de outros grandes equipamentos como 


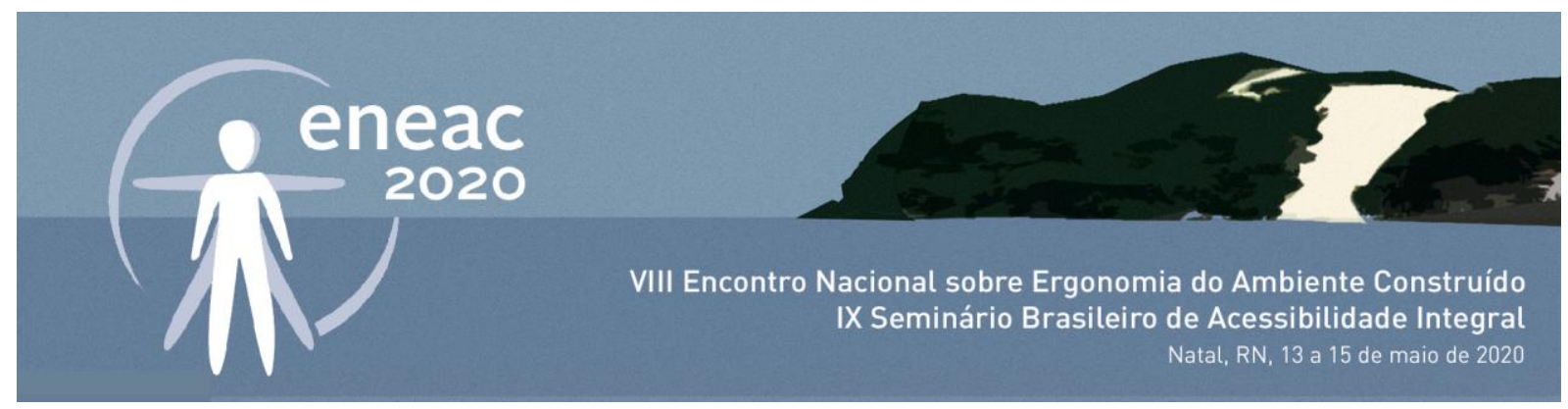

shoppings, universidades e de uma maior proximidade ao aeroporto internacional, fez com que estes dois hotéis de redes internacionais fossem instalados no bairro com o objetivo de se ter a presença de empreendimentos voltados à classe executiva.

Os hotéis das redes A e B, inaugurados em 2016 e 2018 sucessivamente, surgiram com a finalidade de serem pontos de hospedagem com uma funcionalidade mais "enxuta"; diferindo-os dos hotéis localizados tanto na região litorânea norte, mais conhecida pela Avenida Beira Mar, que incluem os bairros - Praia de Iracema, Meireles e Mucuripe, como na área litorânea leste, conhecida como Praia do Futuro I e II. Os hotéis destas duas regiões praieiras proporcionam equipamentos privativos de lazer aos seus hóspedes, além de estarem, normalmente, dispostos frente ao mar.

Os dois hotéis selecionados para esta pesquisa estão localizados no mesmo bairro - Guararapes. Apresentam programas e funções semelhantes. Os dois estão separados pela distância de 600 metros, tornando-os concorrentes diretos na região. Assim, por terem mesmo perfil e estarem localizados em uma região atípica para hotéis, as duas edificações destacaram-se para este trabalho de caráter comparativo.

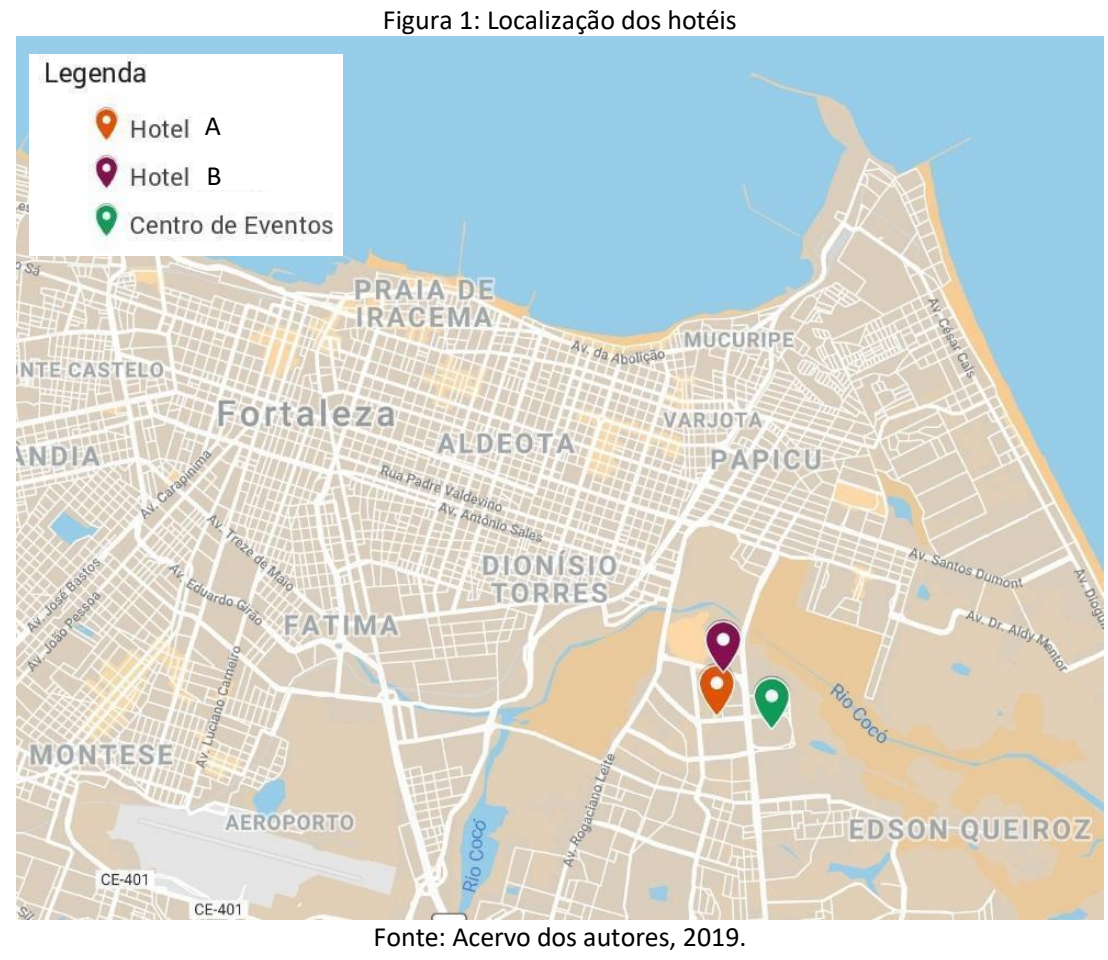

\section{METODOLOGIA}

A metodologia utilizada para esta pesquisa de campo foi a Avaliação Pós-Ocupação (APO) de Ornstein (1992) e Rheingantz et al. (2009) que tem como objetivo a avaliação de desempenho do ambiente construído após sua ocupação, enfatizando o ponto de vista do usuário final do objeto 


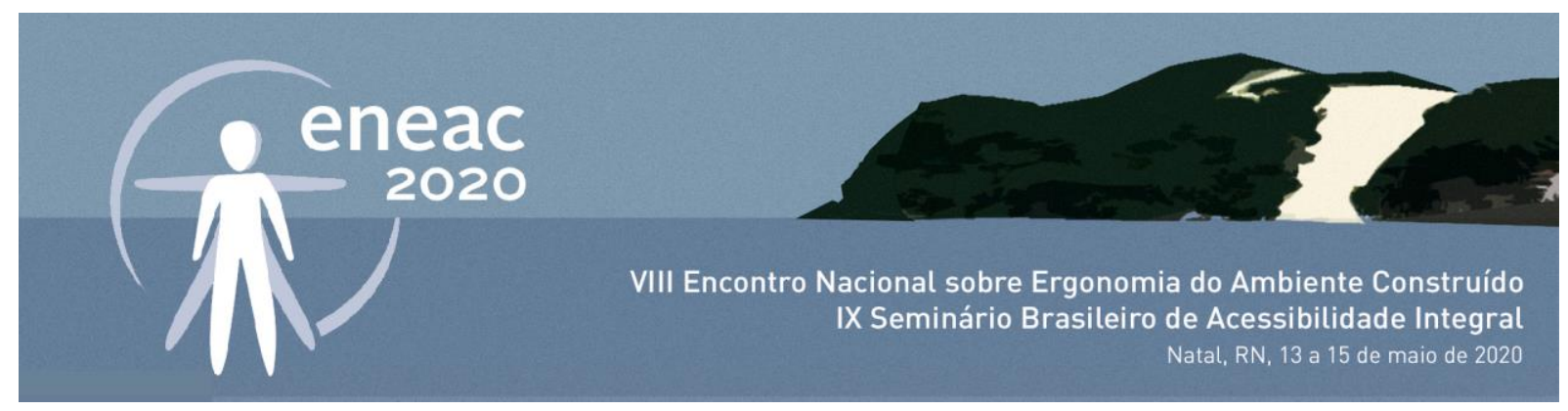

(hóspedes). Como ferramenta de pesquisa, o walkthrough foi aplicado com a finalidade de identificar rapidamente os pontos positivos e negativos de cada hotel (RHEINGANTZ et al., 2009).

Com o levantamento in loco das edificações, incluindo as áreas externas e as dependências internas de cada hotel (exceto áreas restritas aos funcionários) e, observando as recomendações da norma NBR 9050/2015, 16537/2016 e o decreto 5.296, de 2 de dezembro de 2004; pode-se listar os principais pontos a serem avaliados em cada empreendimento. Ressalta-se que, mesmo sabendo que os dois hotéis possuem perfis similares de função e de público, os seus programas arquitetônicos variam em alguns aspectos. Estes aspectos particulares de cada um também foram avaliados, porém não serão destacados neste artigo, pois, tal trabalho é de caráter comparativo.

Para os levantamentos, foi realizado um checklist com itens que já se presumia como típicos em um hotel, enquanto outros itens foram acrescidos durante as visitas. Equipamentos de mensuração e de fotografia foram utilizados para servir de documentação técnica.

Cada levantamento foi realizado com a mesma programação, na qual os pesquisadores fizeram a rota padrão dos hóspedes ao chegarem ao hotel. A rota programada iniciava na área externa do hotel, avaliando os passeios e o estacionamento aberto ao público e, posteriormente, a entrada principal de acesso à edificação. Neste primeiro momento, observamos os seguintes parâmetros:

1 - Passeios: largura e pavimentação do passeio, existência de rebaixamento de guias, obstáculos, piso tátil ou guia de balizamento para deficientes visuais e cegos, e paisagismo aplicado.

2 - Estacionamento aberto ao público: existência de vagas exclusivas para idosos e para pessoas com deficiência.

3 - Acesso à edificação: presença de escada e/ou rampas observando a pavimentação, o guardacorpo e os corrimãos; portas de acesso ao hotel e a presença de algum obstáculo.

Já na segunda parte, interna de cada edificação; o levantamento seguiu para o balcão da recepção e, posteriormente, sala de estar/espera, banheiros e restaurante. Observou-se os seguintes pontos:

1 - Recepção: presença de piso tátil guiando até a recepção, presença de algum mapa de orientação, revestimento do piso, e dimensões do (s) balcão (ões).

2 - Sala de estar/espera: mobiliário e espaço de circulação entre os móveis.

3 - Banheiros: sinalização, abertura e largura dos vãos das portas, disposição das louças, acessórios e barras, e revestimentos utilizados no piso e parede.

4 - Restaurante: disposição das mesas, e dimensões do móvel de exposição dos alimentos.

No terceiro momento da análise, foram levantadas as suítes determinadas por cada hotel como acessíveis e, por fim, os estacionamentos privativos.

1 - Suíte acessível: largura da porta de acesso, espaço para circulação de cadeira de rodas, altura do mobiliário, e banheiro acessível.

2 - Estacionamento privativo: existência de vagas exclusivas para idosos e para pessoas com deficiência, acesso à edificação.

Inicialmente, foi observado a qualidade de acesso ao hotel considerando o tipo de piso, o nivelamento e se existe inclinação transversal adequada. Ainda foi visto a existência de sinalização 

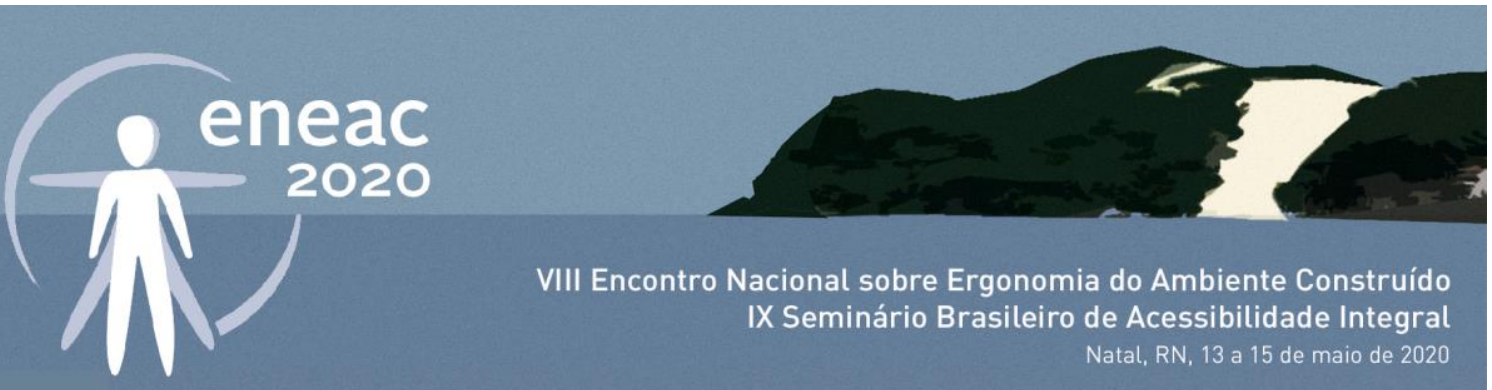

VIII Encontro Nacional sobre Ergonomia do Ambiente Construído IX Seminário Brasileiro de Acessibilidade Integral Natal, RN, 13 a 15 de maio de 2020

visual, compondo uma rota acessível por toda a edificação, para que o usuário possa locomover-se de forma independente, passando pela recepção até as suítes e áreas comuns. As circulações horizontais e verticais devem estar conectadas por sinalização visual, pisos direcionais e/ou guias edificadas, com dimensões estabelecidos pela NBR 9050. Portas, guarda-corpos, mobiliários, elevadores, sanitários, entre outros, devem ter medidas adequadas para que possam ser utilizados igualmente por pessoas com deficiência, obesos, idosos, gestantes e crianças.

\section{RESULTADOS}

Baseado nos critérios listados na metodologia, foi realizado um quadro comparativo de imagens dos mesmos aspectos de cada hotel. Este quadro apresenta a situação atual de cada item, além de descrever se tal solução executada atende ou não a norma NBR 9050/2015 ou se atende parcialmente. Além disso, observou-se, também, se a solução executava necessita de atualização; pois, não sabendo a data dos projetos de ambos hotéis, algumas soluções podem estar conforme a NBR 9050 de 2004.

A legenda para cada situação ficou determinada da seguinte maneira:

Quadro 2: Legenda da avaliação

\begin{tabular}{|l|l|}
\hline & atende a NBR 9050/2015 \\
\hline & atende parcialmente NBR 9050/2015 \\
\hline & não atende a NBR 9050/2015 \\
\hline & atendimento desatualizado (NBR 9050/2004) \\
\hline
\end{tabular}

Fonte: acervo dos autores (2020)

\begin{tabular}{|c|c|c|c|}
\hline \multicolumn{3}{|c|}{ Quadro 3: Levantamento } \\
\hline \multicolumn{3}{|c|}{ PARTE 01 } \\
\hline HOTEL A & \multicolumn{3}{|c|}{ HOTEL B } \\
\hline \multicolumn{3}{|c|}{ Passeio } \\
\hline \\
\hline
\end{tabular}




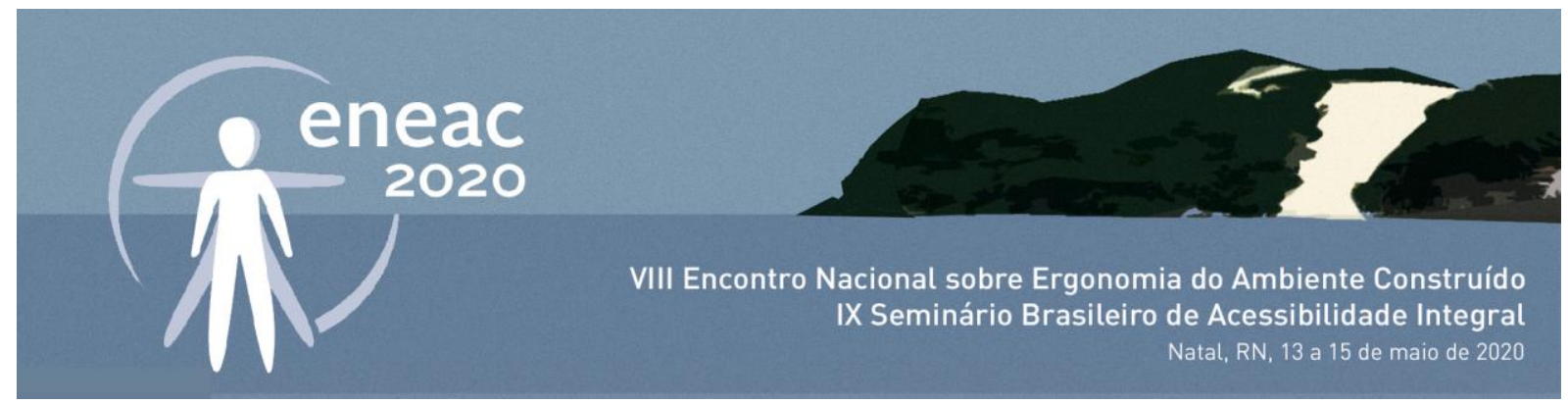

O passeio possui inclinação
transversal acentuada no trecho
de entrada e saída dos veículos.
As jardineiras apresentam
espécies de plantas com folhas
pontiagudas, podendo causar
acidentes. Já a alvenaria das
jardineiras servem parcialmente
como balizadores para deficientes
visuais.

\section{O passeio tem piso levemente} trepidante e com inclinação transversal suave (menor que $3 \%$ ). Apresenta obstáculos no encontro com o passeio do lote vizinho e não há piso tátil e nem qualquer guia de balizamento.
As calçadas devem garantir uma faixa livre para circulação de pedestres sem degrau (mín.

$1,20 \mathrm{~m}$ ). A inclinação transversal máxima deve ser de $3 \%$. 0 acesso de veículos ao lote e estacionamento deve ser feito de maneira a não interferir na faixa livre de circulação de pedestres.

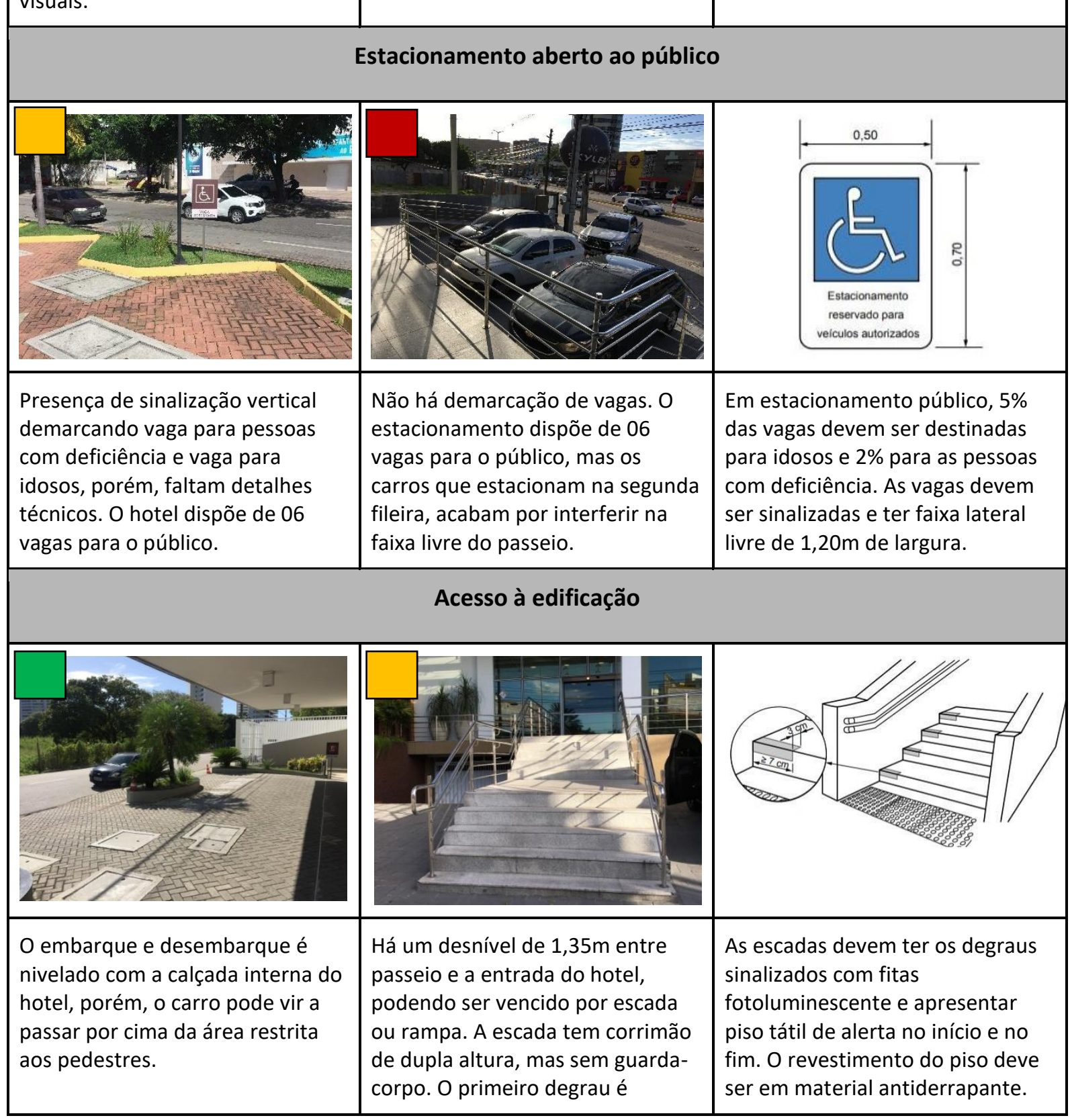




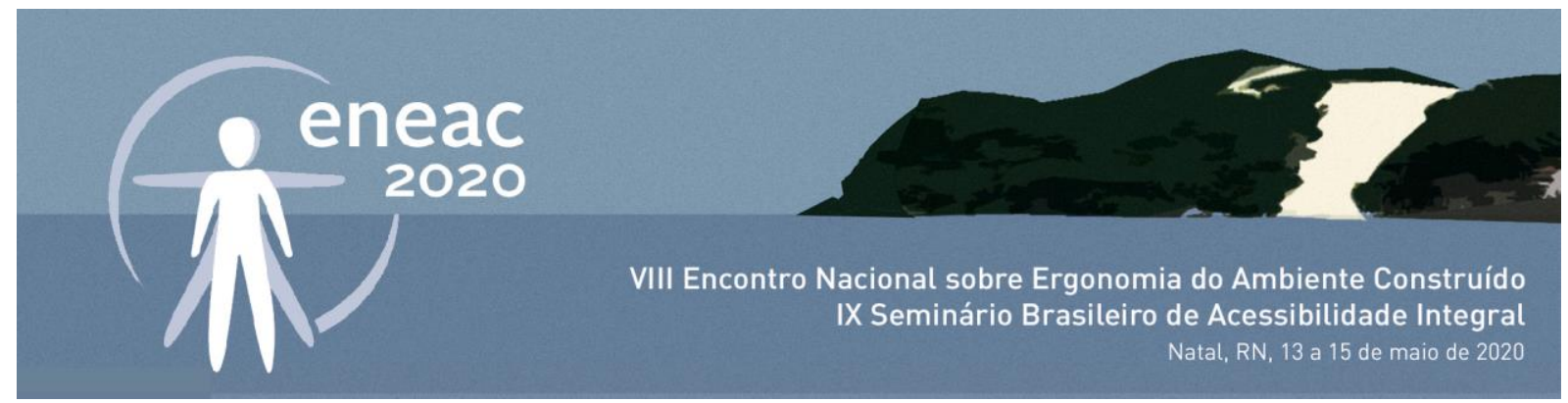

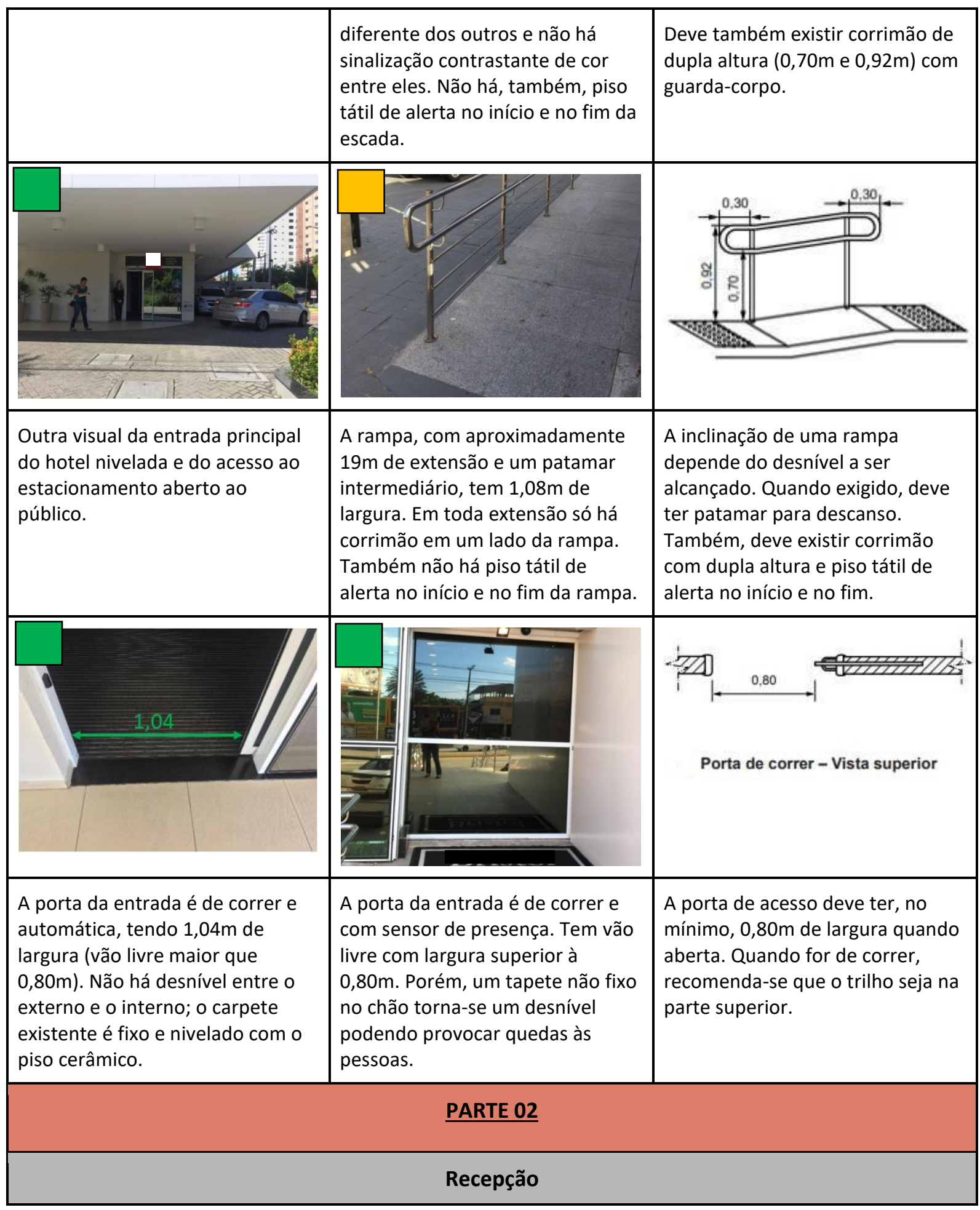




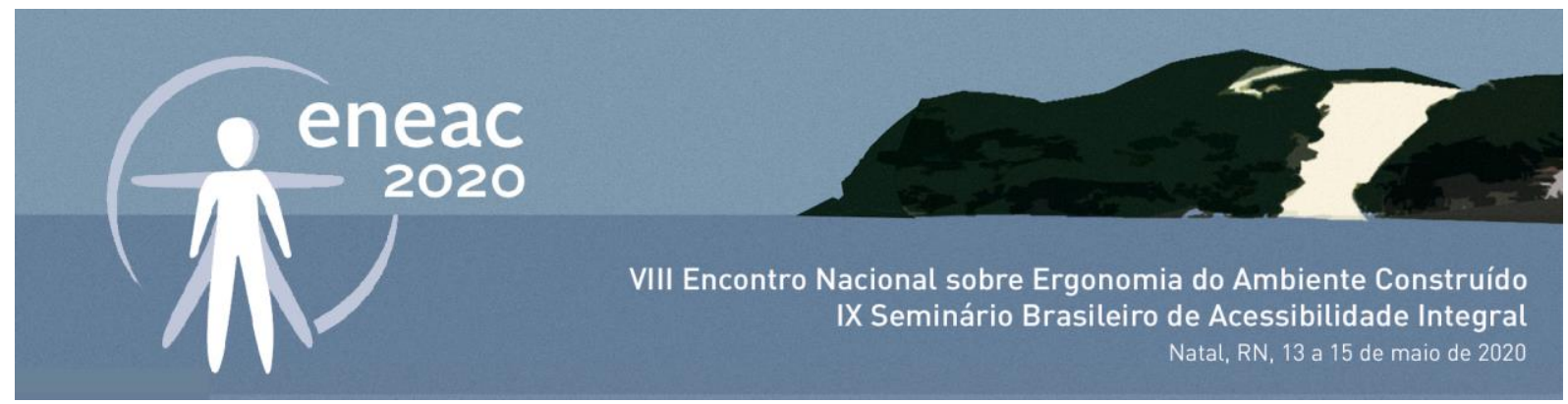

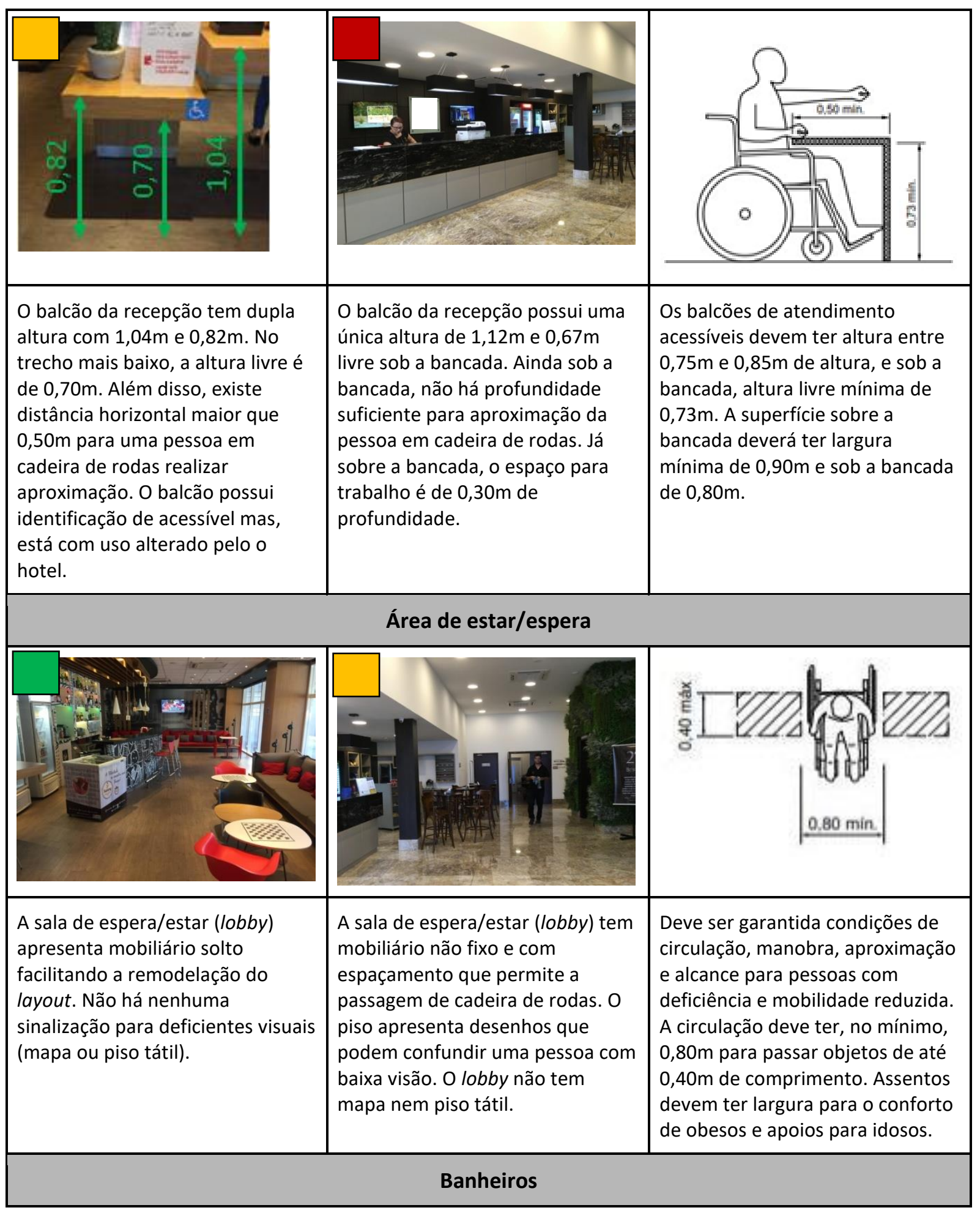



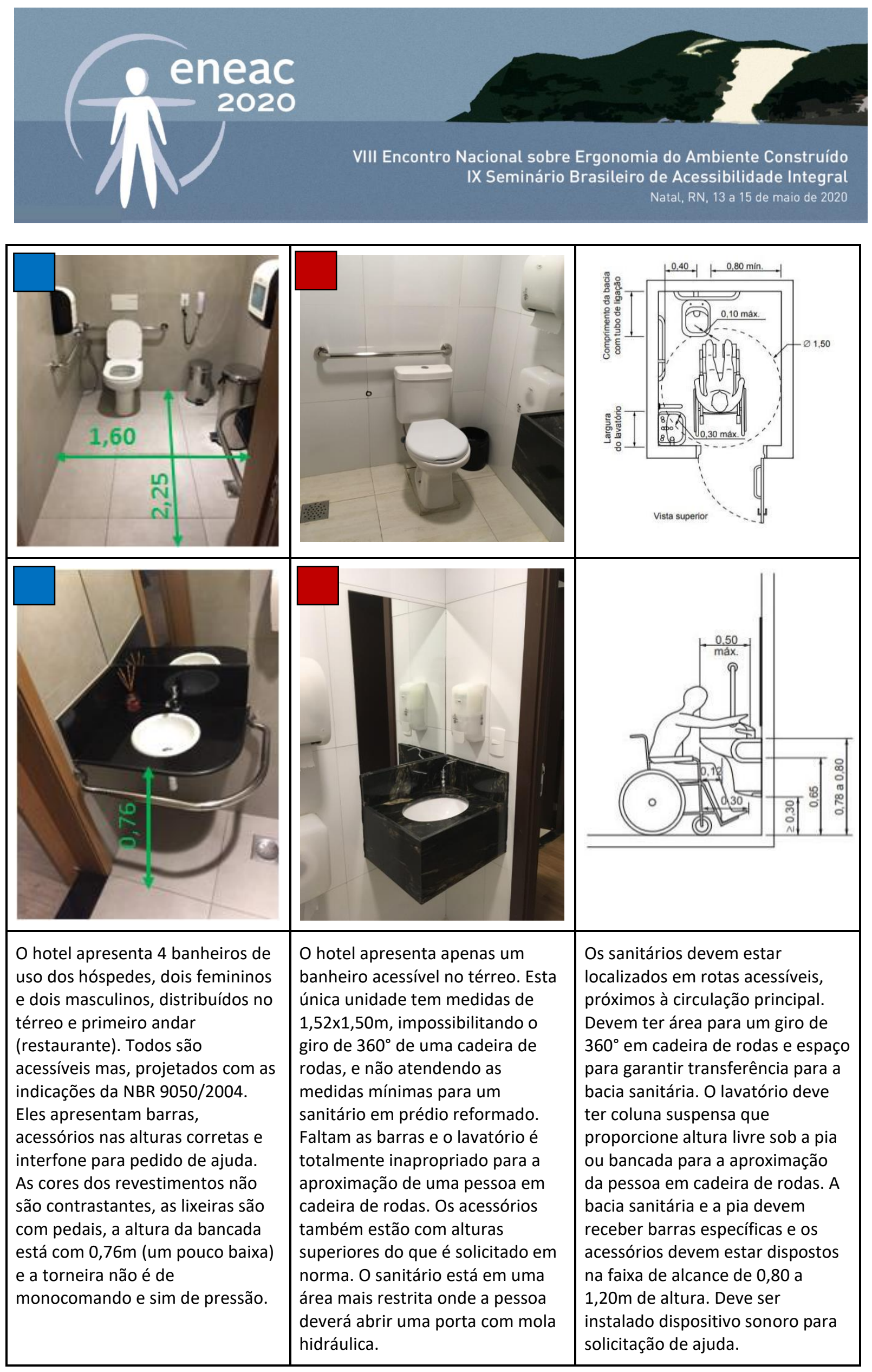

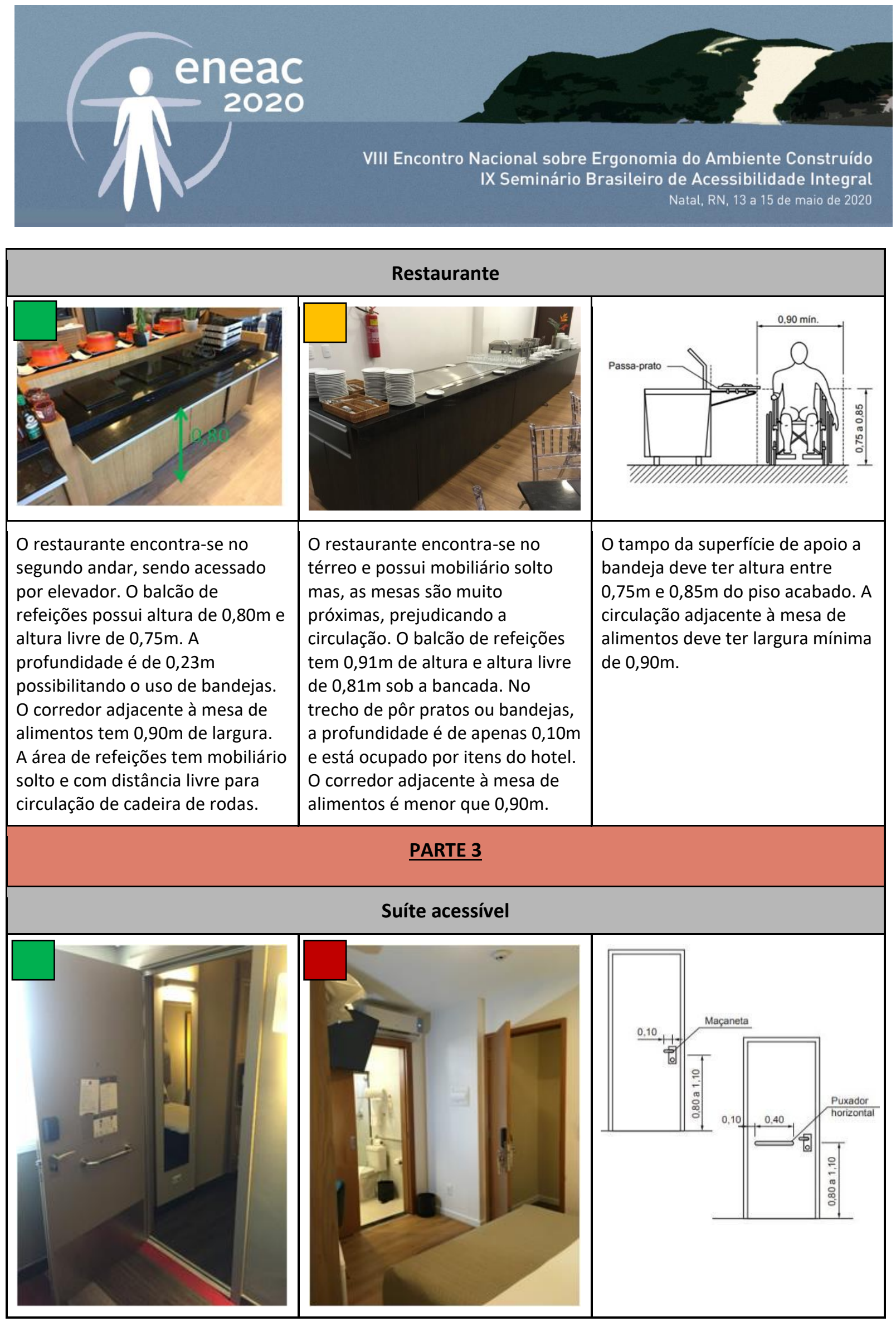

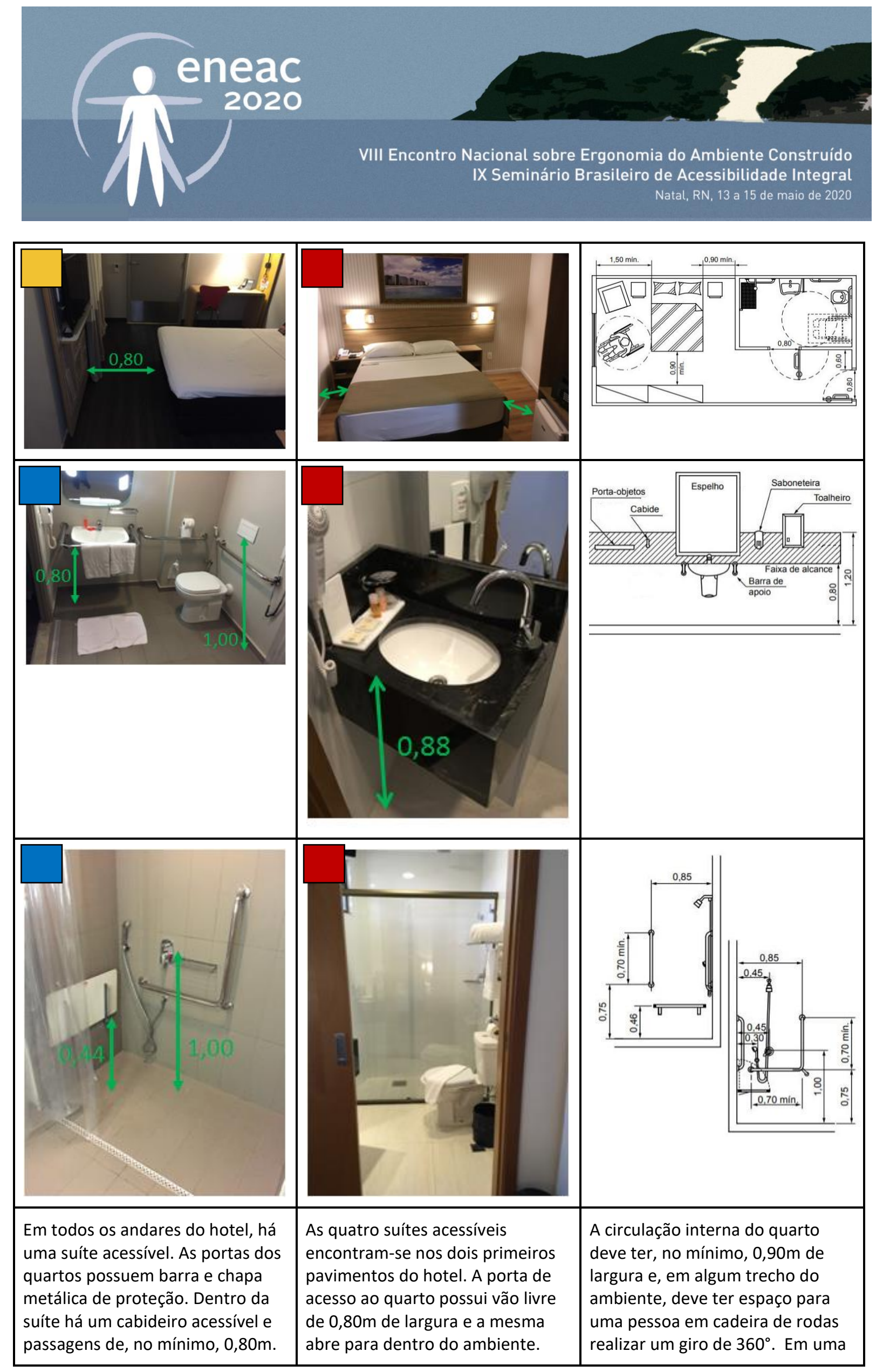


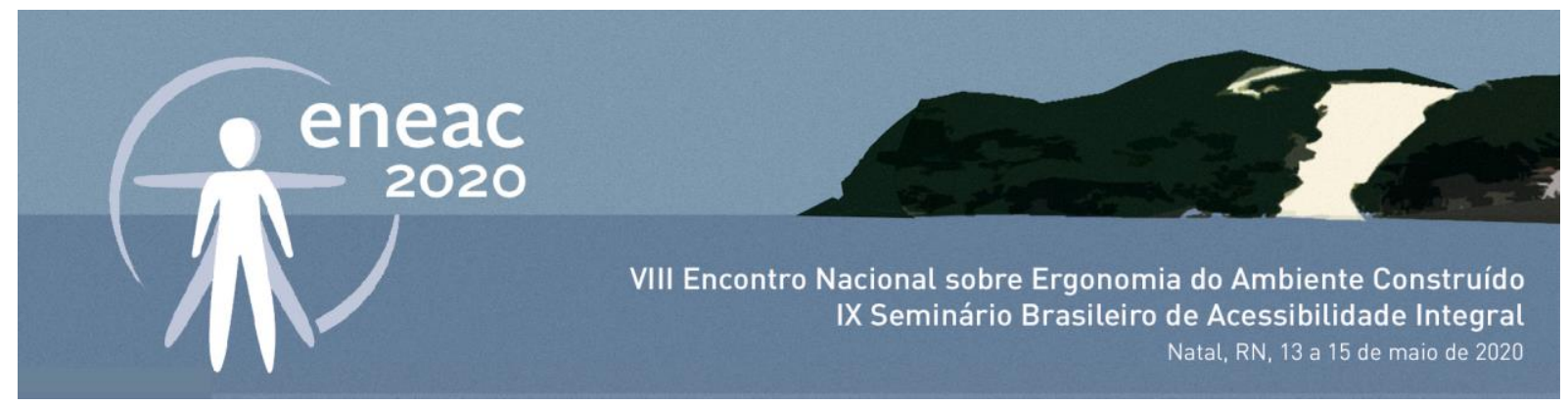

Há uma bancada de estudo com $0,75 \mathrm{~m}$ de altura e $0,70 \mathrm{~m}$ de altura livre sob o tampo. A porta de acesso ao banheiro tem $0,85 \mathrm{~m}$ de vão livre e possui, também, barra e chapa metálica de proteção. 0 banheiro tem área que permite um giro de $360^{\circ}$ em cadeira de rodas. Todos as barras estão de acordo com a NBR 9050/2004, deixando o banheiro desatualizado normativamente. Os revestimentos das paredes e piso não possuem cores contrastantes, podendo confundir uma pessoa de baixa visão. 0 banheiro apresenta interfone de ajuda e alarme de incêndio luminescente para deficientes auditivos. A área de banho possui barras, banco articulado, grelha linear e fechamento em cortina plástica.
Devido a posição dos móveis, uma pessoa em cadeira de rodas não consegue fazer a aproximação lateral da cama. O cabideiro existente é alto, não acessível. A mesa de estudos tem apenas 0,54m de largura, não permitindo, também, a aproximação da pessoa em cadeira de rodas. $\mathrm{O}$ banheiro tem porta de correr com $0,71 \mathrm{~m}$ de largura e apresenta layout inacessível para uma pessoa em cadeira de rodas. Não há barras no lavatório e nem na área de banho. Essa última área é fechada com divisória em vidro que pode provocar acidente sério em caso de queda. das laterais da cama, a largura deve ser de 0,90m para acesso ao móvel. O mobiliário deve ter altura de alcance de 1,20m medida confortável para pessoas em cadeira de rodas. Em quartos de locais de hospedagem devem ser instalados dispositivos de chamada e alarmes de emergência (visuais, sonoros e/ou vibratórios). O banheiro deve ter espaço para um giro de $360^{\circ}$ em cadeira de rodas e acessórios que obedeçam a faixa de alcance entre 0,80 a $1,20 \mathrm{~m}$ de altura. A área de banho deve ter banco articulado e dimensões mínimas de 0,90x0,95m. Assim, como o banheiro, a área de banho também recebe barras. $O$ piso deve ser antiderrapante, nivelado com o resto do banheiro e ter grelha linear para o escoamento das águas.

\begin{tabular}{|c|c|c|}
\hline \multicolumn{3}{|c|}{ Estacionamento Privativo } \\
\hline$-1-$ 圆 回 & & NBR 9050/2004 \\
\hline $\begin{array}{l}\text { O estacionamento privativo } \\
\text { possui vagas preferenciais para } \\
\text { idosos e pessoas com deficiência } \\
\text { com sinalização vertical, mas sem } \\
\text { sinalização horizontal. A porta de } \\
\text { acesso ao hall de elevadores } \\
\text { possui uma rampa com inclinação } \\
\text { acima de } 10 \% \text {. }\end{array}$ & $\begin{array}{l}\text { O estacionamento privativo não } \\
\text { tem demarcação de vagas } \\
\text { prioritárias e possui um desnível } \\
\text { de } 0,08 m \text { para acessar ao piso do } \\
\text { elevador. }\end{array}$ & $\begin{array}{l}\text { O percurso entre as vagas até o } \\
\text { acesso da edificação deve ser sem } \\
\text { obstáculos. Além disso, as vagas } \\
\text { acessíveis devem estar até } 50 \mathrm{~m} \text { do } \\
\text { acesso da edificação. As vagas } \\
\text { para veículos que sejam } \\
\text { conduzidos ou que conduzam } \\
\text { pessoas com deficiência deve ter } \\
\text { um espaço de } 1,20 \mathrm{~m} \text { adicional. }\end{array}$ \\
\hline
\end{tabular}




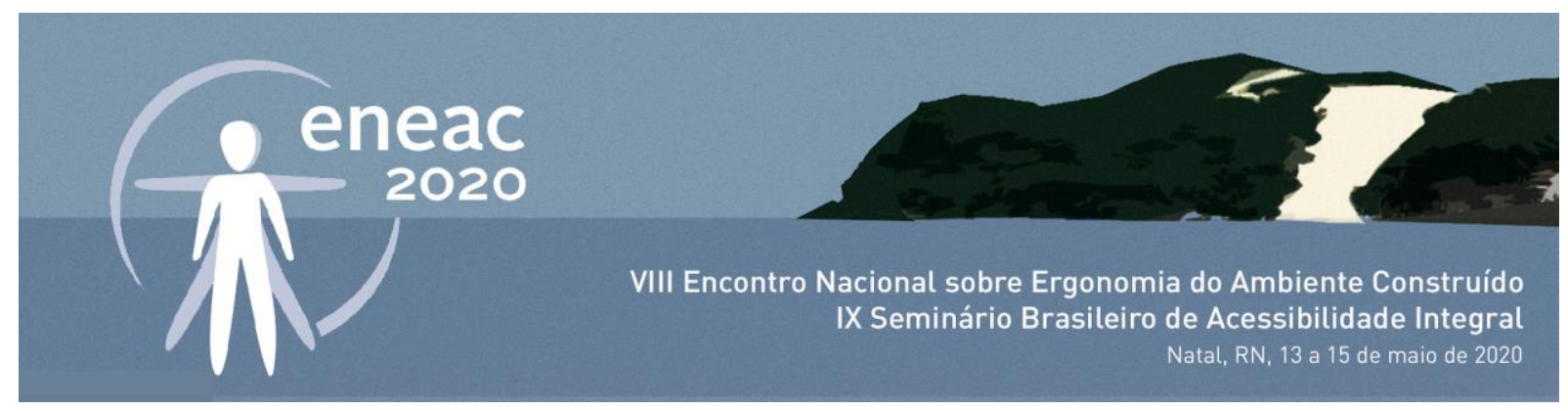

Além destes ambientes comparados no quadro 03, o Hotel B apresentou algumas áreas a mais para o uso dos hóspedes e do público externo: quatro salas para eventos, sendo três no pavimento térreo e uma no último andar da edificação juntamente com a academia. Este último pavimento só é acessado por escadas, inviabilizando o uso dos dois espaços por pessoas em cadeira de rodas e/ou com alguma deficiência.

A circulação vertical do Hotel A é feita por dois elevadores sinalizados com braile e por uma escada de emergência enclausurada; enquanto a do Hotel $B$ é feita por um elevador e também por uma escada. Sobre a circulação horizontal nos andares tipo, a do hotel A possui largura suficiente para percorrer uma pessoa em cadeira de rodas e ainda deixar um espaço livre. Nesta mesma circulação, há uma diferenciação de cor entre piso e parede que auxilia o caminhar de pessoas com baixa visão. Já no hotel B, os corredores são estreitos comprometendo a circulação dos hóspedes mas, as cores do piso e parede são contrastantes.

Ao observar tantas diferenças técnicas entre estes dois novos hotéis com funções similares, coube investigar tal motivo. $O$ que se pôde ver e entender como justificativa de tamanha discrepância entre os dois empreendimentos é que o Hotel A foi construído com a finalidade de ser unicamente um hotel; enquanto o Hotel B foi instalado em uma edificação já construída e reformada para adequar o espaço à função hoteleira.

A problemática de aproveitamento de uma edificação existente para outros fins é a de não garantir, em alguns casos, espaços com dimensões ideais para o uso equitativo do público em geral. Daí, surge a necessidade de pensar se compensará a instalação do empreendimento em uma edificação que não possibilite as reformas essenciais exigidas. O planejamento prévio possibilita descobrir se a edificação tem potencial para desenvolver a atividade específica com estratégias aceitáveis para os seus clientes (PREISER, HARDY, WILHELM, 2017).

\section{CONSIDERAÇÕES FINAIS}

Neste trabalho, pode-se observar que edificações, mesmo com datas recentes de construção, ainda deixam passar problemas construtivos da acessibilidade. Não foram identificadas se estes foram de projeto ou de execução. Além disso, este fato demonstra a falta de conhecimento do que diz as normas e o decreto sobre acessibilidade. Ambos são documentos bastante comentados e disseminados nos campos da arquitetura e da engenharia civil, mas que, ainda necessitam de mais aprofundamento e prática construtiva por parte dos profissionais da área.

As edificações com funções tão específicas como os hotéis, assim como outras edificações que recebem um público diversificado, precisam de maior atenção técnica. São detalhes mínimos que podem refletir bastante no uso democrático do espaço.

Outra questão importante a se ressaltar é o caso de reformas de edificações que dão novas atividades funcionais aos prédios. Além de haver a preocupação em aproveitar o máximo do espaço existente, deve-se ter a justa clareza do que é primordial para o bom funcionamento de tal empreendimento. No caso do Hotel B, onde a edificação foi remodelada, a mudança de função dos espaços refletiu diretamente na circulação e nas dimensões dos ambientes, mas, isso não justifica soluções indesejadas encontradas no levantamento. Este foi o caso do balcão da recepção que, mesmo sendo um mobiliário, não apresentou desenho universal que fosse usado por todos. Assim, 


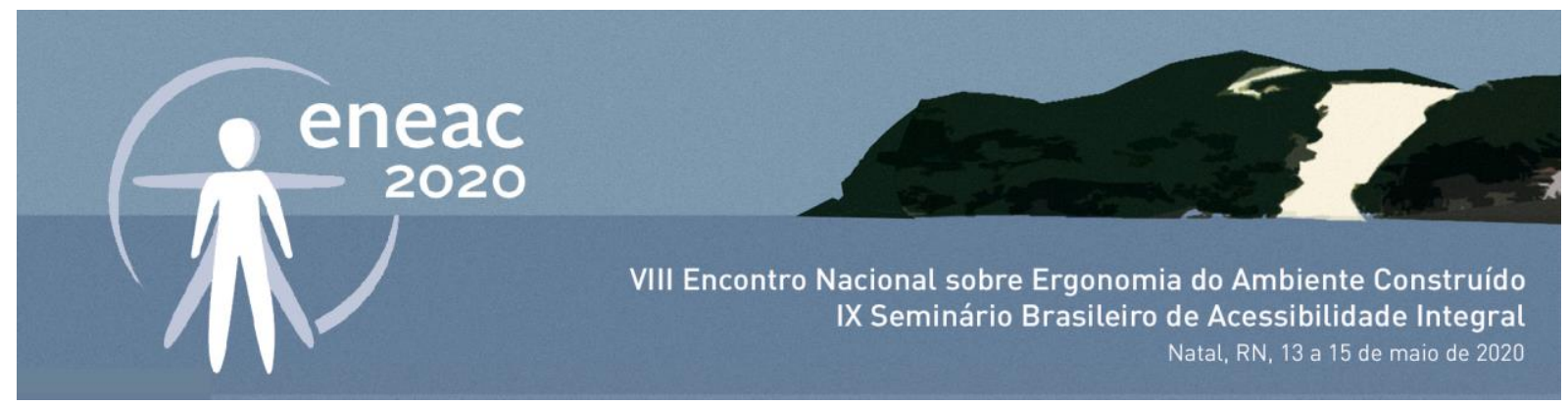

volta-se para questão da falta de conhecimento do que diz a norma e do que seria melhor para os hóspedes.

A especificação do uso da edificação tem que vir acompanhada de uma análise crítica do que será projetado e construído. Neste sentido, a pesquisa demonstra que o projeto deve pensar nos detalhes de acessibilidade dentro do sistema construtivo desde o início de sua concepção; pois, ao tentar adaptar o que fora feito, nem sempre se conseguirá as condições necessárias para alcançar espaços mais amigáveis e democráticos.

\section{AGRADECIMENTOS}

Nossos agradecimentos ao CNPq e FUNCAP pelo auxílio financeiro de cotas de IC em forma de bolsa ao Programa Institucional de Bolsas de Iniciação Científica PIBIC/UFC.

\section{REFERÊNCIAS}

ASSOCIAÇÃO BRASILEIRA DE NORMAS TÉCNICAS. NBR 9050: Acessibilidade a edificações, mobiliário, espaços $e$ equipamentos urbanos. Rio de Janeiro: ABNT, 2015.

ASSOCIAÇÃO BRASILEIRA DE NORMAS TÉCNICAS. NBR 16537: Acessibilidade - Sinalização tátil no piso - Diretrizes para elaboração de projetos e instalação. Rio de Janeiro: ABNT, 2016.

BRASIL. Decreto $N^{\circ}$ 5.296, de 2 de dezembro de 2004. Regulamenta as Leis nos 10.048, de 8 de novembro de 2000, que dá prioridade de atendimento às pessoas que especifica, e 10.098, de 19 de dezembro de 2000, que estabelece normas gerais e critérios básicos para a promoção da acessibilidade das pessoas portadoras de deficiência ou com mobilidade reduzida, e dá outras providências.

IBGE, Censo Demográfico, 2010: Disponível em http://www.ibge.censo2010.gov.br Acesso em: 01/12/2017.

GOVERNO DO ESTADO DO CEARÁ. Indicadores Turísticos 2010-2016. Secretaria de Turismo, 2017.

ORNSTEIN, Sheila; ROMÉRO, Marcelo. Avaliação Pós-Ocupação do Ambiente Construído. São Paulo: Studio Nobel, 1992.

PREISER, W.; HARDY, A.; WILHELM, J. Adaptive Architecture: Changing Parameters and Practice. New York: Routledge, 2017. RHEINGANTZ, P. A.; AZEVEDO, G. A.; BRASILEIRO, A; ALCANTARA, D.; QUEIROZ, M. Observado a qualidade do lugar. Procedimentos para a avaliação pós-ocupação. Rio de Janeiro: PROARQ, 2009.

LIMA, R. O. D. O Reposicionamento de destino turístico: o caso do Centro de Eventos do Ceará, Brasil. Dissertação Centro de Ciências e Tecnologia - Universidade Estadual do Ceará, 2015, pp. 147.

\section{NOTAS}

' Os nomes originais dos hotéis serão preservados neste trabalho. 